\title{
DEM Resolution Impact on the Estimation of the Physical Characteristics of Watersheds by Using SWAT
}

\author{
Waranyu Buakhao and Anongrit Kangrang \\ Faculty of Engineering, Mahasarakham University, Kantharawichai, Maha Sarakham 44150, Thailand \\ Correspondence should be addressed to Anongrit Kangrang; anongrit.k@msu.ac.th
}

Received 26 August 2015; Revised 4 December 2015; Accepted 19 January 2016

Academic Editor: Serji N. Amirkhanian

Copyright ( 2016 W. Buakhao and A. Kangrang. This is an open access article distributed under the Creative Commons Attribution License, which permits unrestricted use, distribution, and reproduction in any medium, provided the original work is properly cited.

\begin{abstract}
A digital elevation model (DEM) is an important spatial input for automatic extraction of topographic parameters for the soil and water assessment tool (SWAT). The objective of this study was to investigate the impact of DEM resolution (from 5 to $90 \mathrm{~m}$ ) on the delineation process of a SWAT model with two types of watershed characteristics (flat area and mountain area) and three sizes of watershed area (about 20,000, 200,000, and 1,500,000 hectares). The results showed that the total lengths of the streamline, main channel slope, watershed area, and area slope were significantly different when using the DEM datasets to delineate. Delineation using the SRTM DEM (90 m), ASTER DEM (30 m), and LDD DEM $(5 \mathrm{~m})$ for all watershed characteristics showed that the watershed sizes and shapes obtained were only slightly different, whereas the area slopes obtained were significantly different. The total lengths of the generated streams increased when the resolution of the DEM used was higher. The stream slopes obtained using the small area sizes were insignificant, whereas the slopes obtained using the large area sizes were significantly different. This suggests that water resource model users should use the ASTER DEM as opposed to a finer resolution DEM for model input to save time for the model calibration and validation.
\end{abstract}

\section{Introduction}

Computer technologies can provide additional tools for geological mapping, which may improve the agreement of the determined geological units with the terrain topography; such a tool is digital elevation model (DEM), which is a digital map of the elevation of an area on the Earth [1-3]. DEM is useful for automatic creation of input data prepared for hydrological and hydraulic models, such as the soil and water assessment tool (SWAT) model, the hydrologic engineering center-river analysis system (HEC-RAS), and the hydrologic engineering center-hydrologic modeling system (HECHMS) [4-6]. DEM can be used to represent the physical parameters of the watershed in terms of the flow direction, drainage network, and drainage slopes. The performance of the model varies depending on the available input data $[7,8]$. Basic DEM resolution, or raster size, is always a compromise between the level of detail needed for computation, the accuracy of the data, and the total computing power and time resources that can be allocated [9]. The accuracy of the DEM data must be monitored to enable the best selection for use in preparing the DEM base model because this is the key to the success of the model results. A subsequent issue is that grid size is suitable for each kind of terrain and the size of the area of interest. The resolution of the Geographic Information System (GIS) data is closely associated with the computation speed in the spatial analysis. When the computing time is too long to run a model at a high resolution, SWAT users may use coarser resolution DEM data to speed up the computation procedure. The Environmental Protection Agency of the United States Geological Survey (EPA-USGS) DEM and $30 \mathrm{~m}$ grid DEM (NED dataset) were employed to investigates the effect of the DEM resolution on the delineation of three catchment areas in Mississippi, and it was found that the resolution of the elevation data affected the watershed delineation by providing more subbasins (for the same area) when using coarser datasets; that is, lower resolution produces further segmentation of a watershed while higher resolution datasets allow better delineation of flat areas when the Advanced Space-Bone Thermal Emission 
and Reflection Radiometer (ASTER) and the Shuttle Radar Topography Mission (SRTM) were applied to delineate the watersheds, and the results showed that both DEMs were suitable for glacier delineation [10].

A SWAT model is the most commonly used tool to study hydrological estimations. Moreover, the objective of SWAT's development was to predict the impact of management on water, sediment, and agricultural chemical yields in large ungagged basins [11]. SWAT is a physically based, semidistributed watershed-scale model that has been used extensively to predict the impact of land management practices on water, sediment, and agricultural chemical transport [12]. SWAT was applied to the $2,530 \mathrm{~km}^{2}$ Chaliyar River Basin in Kerala, India, to investigate the influence of the model parameters, and the result indicated that there may be greater uncertainty in SWAT stream flow estimates as the size of the watershed increases [6]. Most of the studies carried out have been on the effects ranging from $30 \times 30 \mathrm{~m}$ up to 1000 $\times 1000 \mathrm{~m}$ DEM grid sizes, but not using higher resolution datasets at a $5 \mathrm{~m}$ DEM grid size. The impact of spatial input data resolution (from 20 to $500 \mathrm{~m}$ ) on hydrological parameters in a flat watershed has been studied in central Iowa (USA) [13]. In addition, the impact of DEM resolution (from 20 to $1,500 \mathrm{~m}$ ) on SWAT-simulated streamflow has been studied for the Johor River Basin, Malaysia [14]. Currently, higher resolutions of DEM are freely available, for example, the $90 \mathrm{~m}$ grid DEM (SRTM DEM) and the $30 \mathrm{~m}$ grid DEM (ASTER DEM). Particularly in Thailand, a $5 \mathrm{~m}$ grid DEM was developed by the Land Development Department for government organizations to use free of charge.

In Thailand there have been no studies on the DEM grid size, resolution time, and watershed parameters that were used to prepare the hydrological models to estimate runoff, stream flow, and other hydrological parameters in GIS hydrological models. This study investigated the algorithms used and emphasized the problems that can be encountered during the use of DEM data and attendance time to run all the processes using a personal computer (PC). The primary focus of this work was not the accuracy of the elevation data itself, but the attributes derived from them. An application was used on samples taken from the Chi River Basin and the Ping River Basin in Thailand. In addition, the study compared different resolutions, from $5 \mathrm{~m}$ to $90 \mathrm{~m}(5 \mathrm{~m}, 30 \mathrm{~m}$, and $90 \mathrm{~m})$, used in the automatic delineation techniques.

\section{Methodology}

2.1. Study Area. Two characteristics of the areas were considered in this study: flat areas and mountainous areas, as shown in Figure 1. The site of the mountainous area was located between longitudes 259997-340000E and latitudes $1763937-1826002 \mathrm{~N}$ in Chiang Mai Province, Thailand. The total grid used area was 14,400 hectares. The mountainous area dominates most parts of the watershed.

For flat land areas, the first area was located between longitudes 285000-301019E and latitudes 1770002-1753451N in the Huai-Por-Phan watershed. The total grid area used was 26,500 hectares. The second area was located between longitudes 277982-308567E and latitudes 1809520-1866770N in

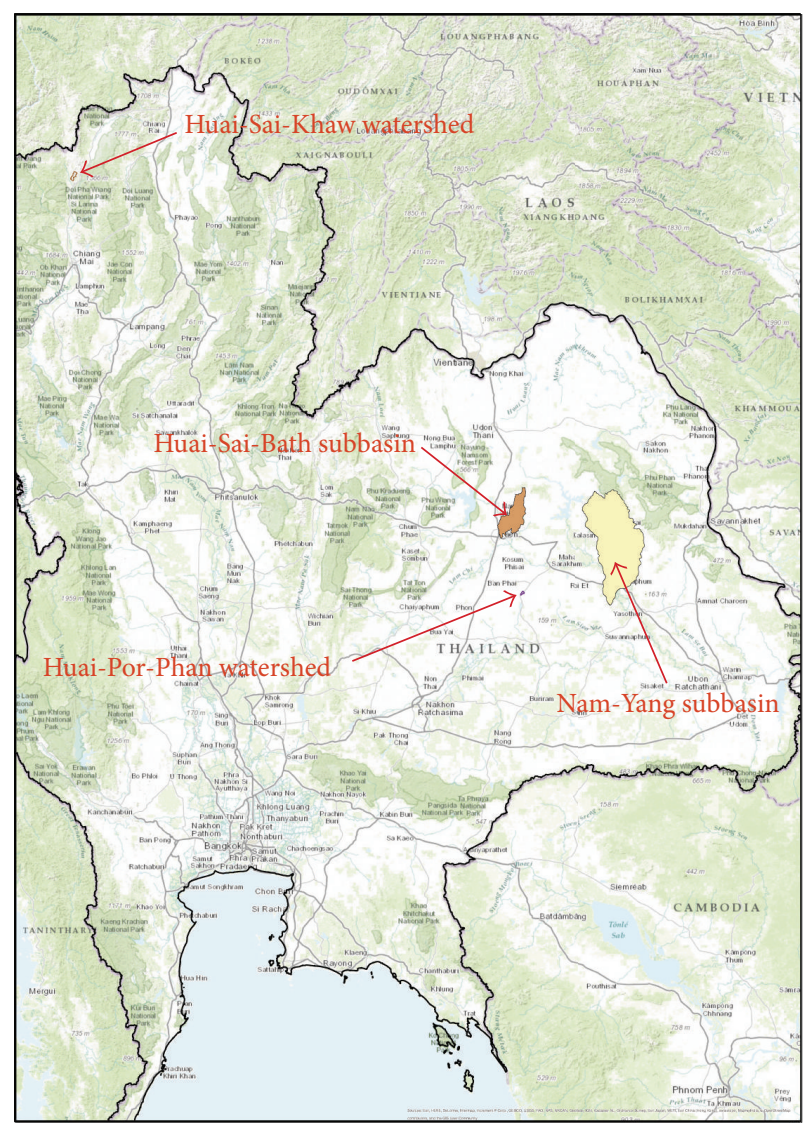

Figure 1: Study area.

the Huai-Sai-Bath subbasin. The total grid area used was 175,000 hectares. The third area was located between longitudes 339997-448007E and latitudes 1741997-11880002N in the Nam-Yang subbasin. The total grid area used was $1,490,000$ hectares.

2.2. Data Collection: DEM. DEM data came from three sources: local LDD DEM, ASTER DEM, and SRTM DEM. Firstly, the LDD DEM was in the grid format data provided by the Land Development Department, Thailand, 2008. Secondly, the ASTER DEM is a new global 1 arc second $(30 \mathrm{~m})$ elevation dataset that was released in June 2009 by METI (Ministry of Economy, Trade, and Industry), Japan, and NASA (National Aeronautics and Space Administration), USA (ERSDAC, 2009). The ASTER $30 \mathrm{~m}$ dataset used in the study area was downloaded from the related website (http://gdem.ersdac.jspacesystems.or.jp/search.jsp). Thirdly, the SRTM DEM is the result of a collaborative effort by NASA, USA (CGIAR-CSI, 2009). The SRTM3 DEM dataset used in the study was downloaded from the website (http://csi.cgiar.org/). The characteristics of the DEMs are shown in Table 1. Watershed shapefiles from the Department of Water Resources, Thailand, 2009, and a topographic 1:50,000 scale map with manually digitized watershed boundaries were used to compare the medium and large sized areas. 
TABLE 1: Detail of DEM sourses.

\begin{tabular}{lccc}
\hline Items & LDD DEM & ASTER DEM & SRTM3 DEM \\
\hline Distribution & LDD & ASTER & NASA/USGS \\
Release year & 2004 & 2009 & 2003 \\
Posting interval & $5 \mathrm{~m}$ & $30 \mathrm{~m}$ & $90 \mathrm{~m}$ \\
DEM accuracy (standard deviation) & $2-4 \mathrm{~m}$ & $7-14 \mathrm{~m}$ & $10 \mathrm{~m}$ \\
DEM coverage & Thailand & $83^{\circ} \mathrm{N}-83^{\circ} \mathrm{S}$ & $60^{\circ} \mathrm{N}-56^{\circ} \mathrm{S}$ \\
\hline
\end{tabular}

2.3. Soil and Water Assessment Tool. SWAT has an auto delineation tool used in the current modeling of the watershed hydrology GIS system. SWAT is a multipurpose environmental analysis system that integrates GIS, watershed data, assessment, and modeling tools. The maps and parameters were extracted by the ArcGIS interface of the SWAT extension as these tools are the most well-known, accessible, and widely utilized, to compare the results, except for the Haui-Sai-Bath subbasin and the Nam-Yang subbasin watershed shapefiles from the DWR that were employed to enable comparisons to be considered. SWAT is a physically based continuous model. The subwatersheds were delineated using the eight directional flow algorithms (D-8 method). The D-8 method is a simple method that can be used to simulate the flow directions.

The method used the D-8 algorithm that assigned a flow direction to the cell in the center by considering the direction of the largest drop in elevation. It can generate stream networks and watershed delineation. Watersheds were created based on the DEM that represented the direction of the water flow $[15,16]$.

\section{Results and Discussion}

The productivity when using all the DEMs will be considered with regard to three aspects of (1) area characteristics (size, shape, and slope of area), (2) length of stream, and (3) slope of main stream. Each aspect was considered for four watersheds (Huai-Sai-Khaw, Huai-Por-Phan, Huai-Sai-Bath, and NamYang subbasins). Certain physical properties of the watersheds significantly affected the characteristics of the runoff and, as such, are of great interest in hydrologic analyses. The principal watershed characteristics are as follows: (1) area of watershed: it reflects the volume of water that can be generated from a rainfall; (2) shape of watershed: the shape of a watershed influences the shape of its characteristic hydrograph; (3) length of watershed: this length is usually used in computing a time parameter, which is a measure of the travel time of water through a watershed; and (4) slope of watershed: watershed slope affects the momentum of runoff.

3.1. Impact of Area Characteristics (Size, Shape, and Slope of Area). In this study, the principal watershed characteristics were considered in terms of the impact on the hydrological response. Watershed parameters (size, shape, and slope of area) were automatically extracted using different resolution DEMs for the same area. The LDD DEM watershed delineation was used as the base point to compare the size of

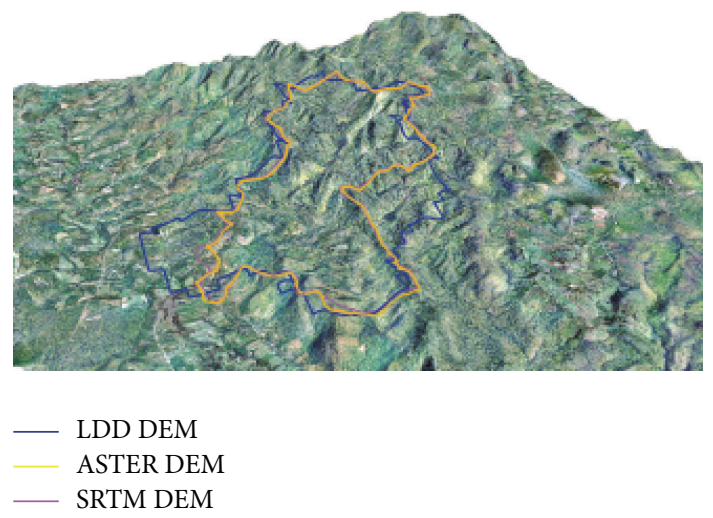

FIGURE 2: Watershed delineation for Huai-Sai-Khaw watershed.

TABLE 2: Intersected areas between various DEMs extracted in HuaiSai-Khaw watershed.

\begin{tabular}{lcc}
\hline Watershed & ASTER versus LDD & SRTM versus LDD \\
\hline Huai-Sai-Khaw & $97.55 \%$ & $95.20 \%$ \\
\hline
\end{tabular}

TABLE 3: Sizes of areas extracted from DEMs of Huai-Sai-Khaw watershed.

\begin{tabular}{lcc}
\hline DEM & Area $\left(\mathrm{km}^{2}\right)$ & Area slope $(\%)$ \\
\hline LDD & 22.19 & 36.09 \\
ASTER & 22.07 & 26.89 \\
SRTM & 26.90 & 15.97 \\
\hline
\end{tabular}

the watershed. The simplest way to compare the efficiency of various DEMs in the same area is a visual comparison, and intersected areas between different DEMs were employed to give more information.

Figure 2 shows the area delineation of Huai-Sai-Khaw watershed (representative of a small mountainous area) using LDD DEM, ASTER DEM, and SRTM DEM. It indicated that the LDD DEM and ASTER DEM shapes were similar, while the shape that was obtained from the SRTM DEM was quite different. In addition, the intersected areas between the various DEMs and extracted watersheds when they are superimposed are included in Table 2.

The area size delineations when using the ASTER DEM and LDD DEM were slightly different, while for the SRTM DEM the difference was $21.8 \%$. The area slopes created from the SRTM DEM and LDD DEM were quite different, whereas the difference in the average area slopes created by the ASTER DEM and LDD DEM was $25.51 \%$, as shown in Table 3. 
TABLE 4: Intersected area between various DEMs extracted in HuaiPor-Phan watershed.

\begin{tabular}{lcc}
\hline Watershed & ASTER versus LDD & SRTM versus LDD \\
\hline Huai-Por-Phan & $94.03 \%$ & $84.47 \%$ \\
\hline
\end{tabular}

TABle 5: Size of area extracted from DEMs of Huai-Por-Phan watershed.

\begin{tabular}{lcc}
\hline DEM & Area $\left(\mathrm{km}^{2}\right)$ & Area slope \\
\hline LDD & 6.38 & 2.53 \\
ASTER & 6.55 & 2.88 \\
SRTM & 6.02 & 1.58 \\
\hline
\end{tabular}

TABLE 6: Intersected area between various DEMs extracted from Huai-Sai-Bath subbasin.

\begin{tabular}{lccc}
\hline Watershed & $\begin{array}{c}\text { ASTER } \\
\text { versus } \\
\text { LDD }\end{array}$ & $\begin{array}{c}\text { SRTM } \\
\text { versus } \\
\text { LDD }\end{array}$ & $\begin{array}{c}\text { DWR } \\
\text { versus } \\
\text { LDD }\end{array}$ \\
\hline $\begin{array}{l}\text { Huai-Sai- } \\
\text { Bath } \\
\text { (medium } \\
\text { flat area) }\end{array}$ & $95.60 \%$ & $95.57 \%$ & $90.38 \%$ \\
\hline
\end{tabular}

Figure 3 shows the area delineation of Huai-Por-Phan subbasin (representative of a small flat area) when using the LDD DEM, ASTER DEM, and SRTM DEM. It shows that the obtained shapes were similar. Moreover, these shapes were considered in terms of the intersected area between the various DEMs, as shown in Table 4. The results indicated that the intersection between the LDD DEM shape and the ASTER DEM shape was higher than the intersection between the LDD DEM shape and SRTM DEM shape.

The area size delineation when using the ASTER DEM and the LDD DEM was slightly different. The area delineation when using the ASTER DEM against the LDD DEM was 2.6\% and for the LDD DEM against the SRTM DEM the difference was $8.1 \%$. The difference in the average area slope created from the ASTER DEM and LDD DEM was $13.56 \%$ and the difference between the area created from the SRTM DEM and LDD DEM was $37.6 \%$, as shown in Table 5.

Figure 4 presents the obtained area delineation for HuaiSai-Bath subbasin (representative of medium flat area) when using LDD DEM, ASTER DEM, and SRTM DEM. The results showed that the obtained shapes and sizes were similar. In addition, the extracted watersheds were similar, as shown in Table 6.

The area size delineations when using the ASTER DEM and the LDD DEM were slightly different. The area delineation when using the ASTER DEM against the LDD DEM was $1.89 \%$ and for the LDD DEM against the SRTM DEM the difference was $3.08 \%$. When comparing to the shapefile from the DWR (DWR, 2009) with the watershed extracted from the LLD DEM a difference of $8.12 \%$ was obtained. The difference in the average area slope from the ASTER DEM and the LDD DEM was $44.31 \%$, and the difference between the area created from the SRTM DEM and the LDD DEM was $44.63 \%$, as shown in Table 7 .

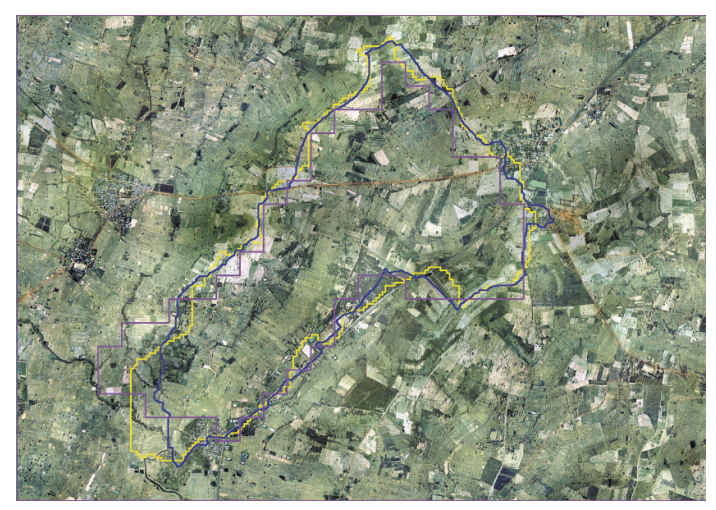

$$
\begin{array}{ll}
\text { ASTER DEM } \\
-\quad \text { LDD DEM } \\
\text { SRTM DEM }
\end{array}
$$

FIGURE 3: Watershed delineation for Huai-Por-Phan watershed.

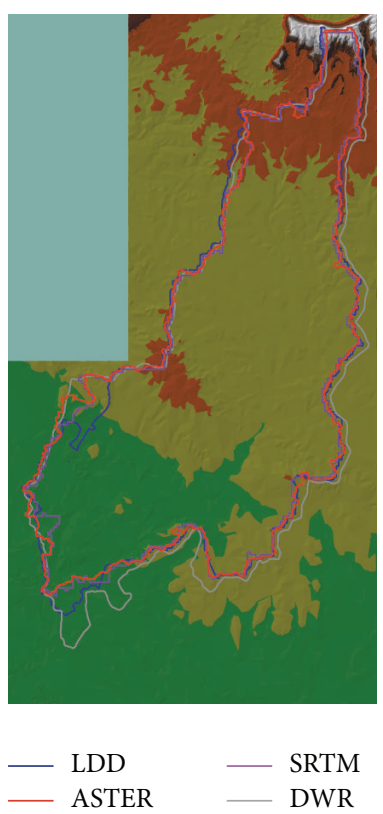

Figure 4: Watershed delineation for Huai-Sai-Bath subbasin.

Figure 5 shows the area delineation of the Nam-Yang subbasin (representative of large size flat area) when using LDD DEM, ASTER DEM, and SRTM DEM. They were not significantly different. The area delineations when using the ASTER DEM and the LDD DEM, as shown in Figure 4, gave a good match between their shapes of the watersheds. The intersected areas between the various DEM extracted watersheds showed that they all have high areas superimposed, as shown in Table 8.

The area size delineation when using the ASTER DEM and the LDD DEM was slightly different. The area delineation when using the ASTER DEM against the LDD DEM was 0.99\% and the LDD DEM against the SRTM DEM gave a difference of $0.16 \%$. When comparing the shapefile from the DWR with the watershed extracted from the LLD DEM, the difference was $23.63 \%$. The difference in the average area 


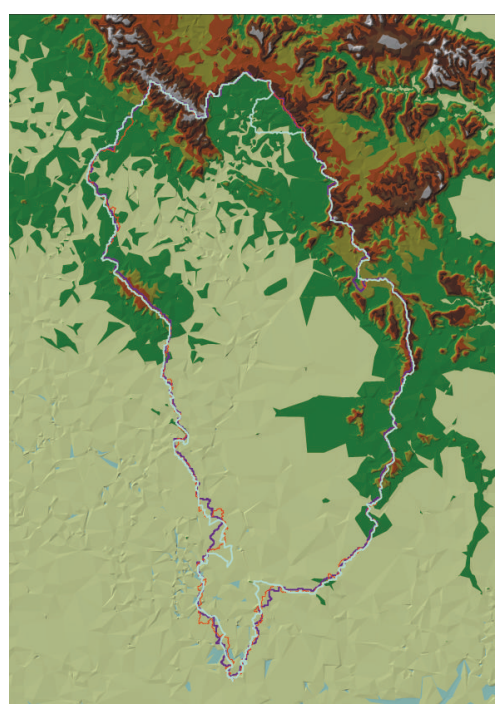

\section{- ASTER DEM \\ - LDD DEM \\ — SRTM DEM}

Figure 5: Watershed delineation for Nam-Yang subbasin.

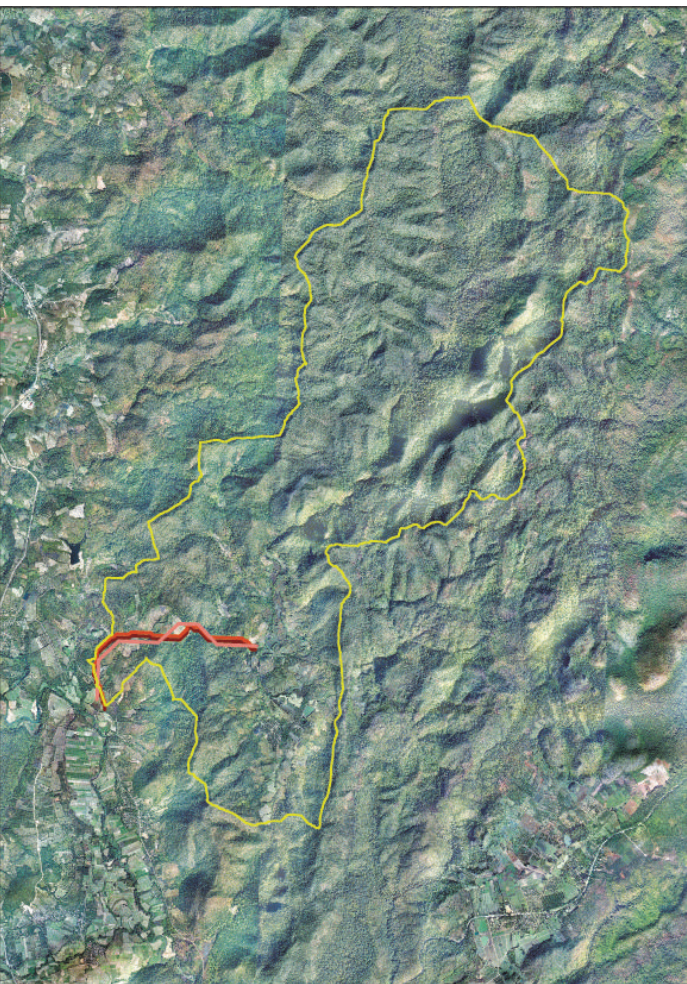

LDD DEM

ASTER DEM

— SRTM DEM

FIGURE 6: Stream lengths extracted from DEMs of Huai-Sai-Khaw watershed.
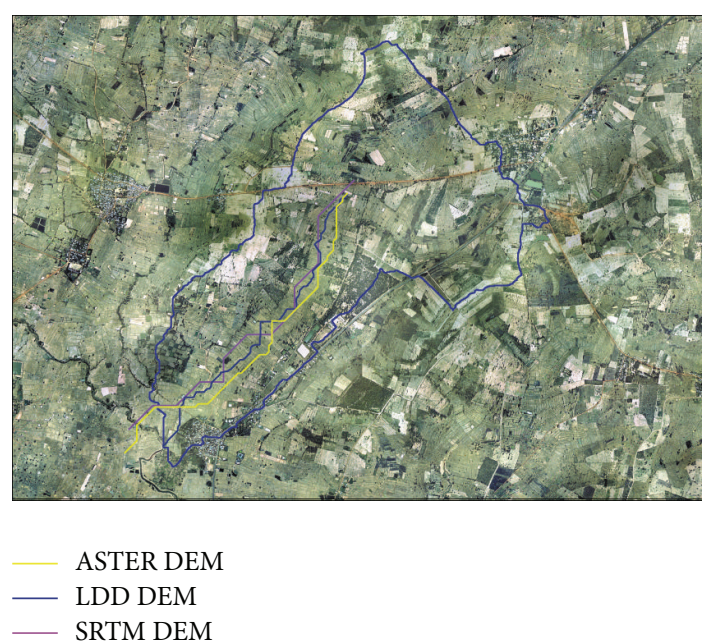

FIGURE 7: Stream lengths extracted from DEMs of Huai-Por-Phan watershed.

TABLe 7: Size of area extracted from DEM of Huai-Sai-Bath subbasin.

\begin{tabular}{lcc}
\hline DEM & Area $\left(\mathrm{km}^{2}\right)$ & Area slope \\
\hline LDD & 625.43 & 2.67 \\
ASTER & 613.79 & 3.86 \\
SRTM & 594.87 & 1.48 \\
\hline
\end{tabular}

TABLE 8: Intersected area between various DEMs extracted from Nam-Yang subbasin.

\begin{tabular}{lccc}
\hline Watershed & $\begin{array}{c}\text { ASTER } \\
\text { versus } \\
\text { LDD }\end{array}$ & $\begin{array}{c}\text { LDD } \\
\text { versus } \\
\text { SRTM }\end{array}$ & $\begin{array}{c}\text { LDD } \\
\text { versus } \\
\text { DWR }\end{array}$ \\
\hline $\begin{array}{l}\text { Nam-Yang } \\
\text { (large flat } \\
\text { area) }\end{array}$ & $97.67 \%$ & $97.87 \%$ & $80.59 \%$ \\
\hline
\end{tabular}

TABle 9: Size of area extracted from DEM of Nam-Yang subbasin.

\begin{tabular}{lcc}
\hline DEM & Area $\left(\mathrm{km}^{2}\right)$ & Area slope \\
\hline LDD & $3,829.36$ & 1.47 \\
ASTER & $3,867.88$ & 2.97 \\
SRTM & $3,861.54$ & 1.24 \\
DWR & 4734.31 & - \\
\hline
\end{tabular}

slope created from the ASTER DEM and the LDD DEM was $34.81 \%$ and the difference between the area created from the SRTM DEM and the LDD DEM was $43.7 \%$, as shown in Table 9.

3.2. Impact of Stream Length. To understand and analyze the facility of the drainage system of a watershed, the total length of the streams and the number of tributaries are the important parameters for drainage evaluation. In this study the channel network extractions were carried out as shown in Figures 69. 

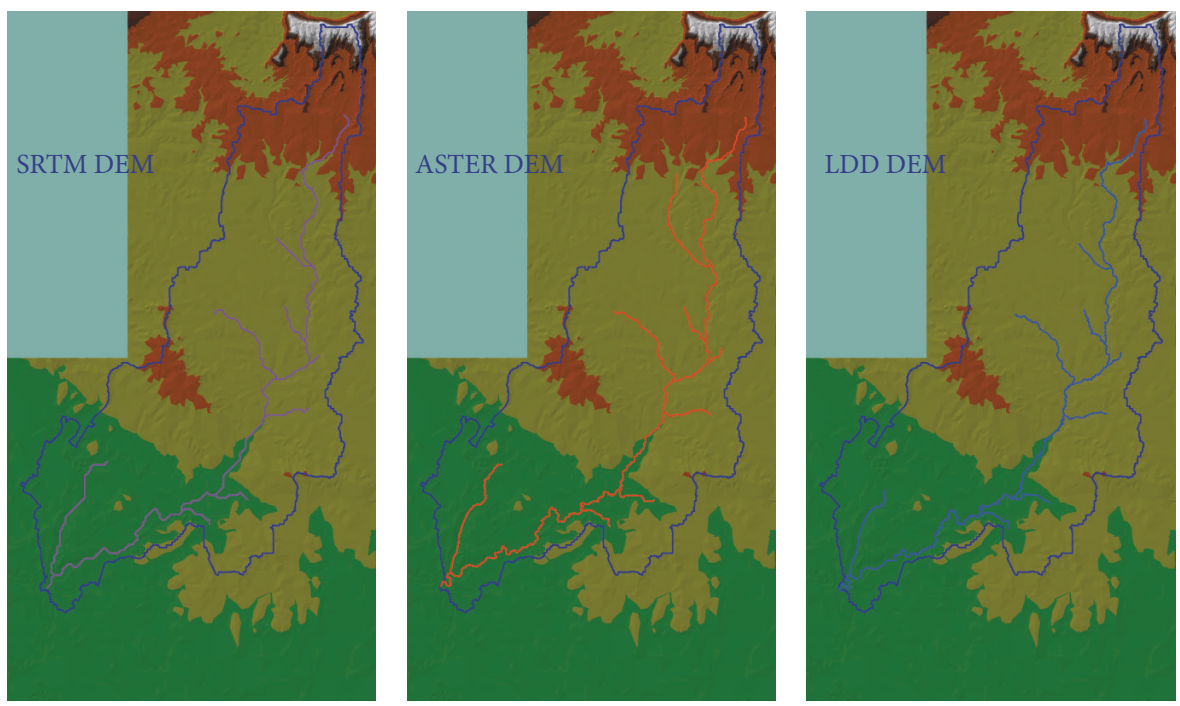

FIGURE 8: Stream lengths extracted from DEMs of Huai-Sai-Bath subbasin.
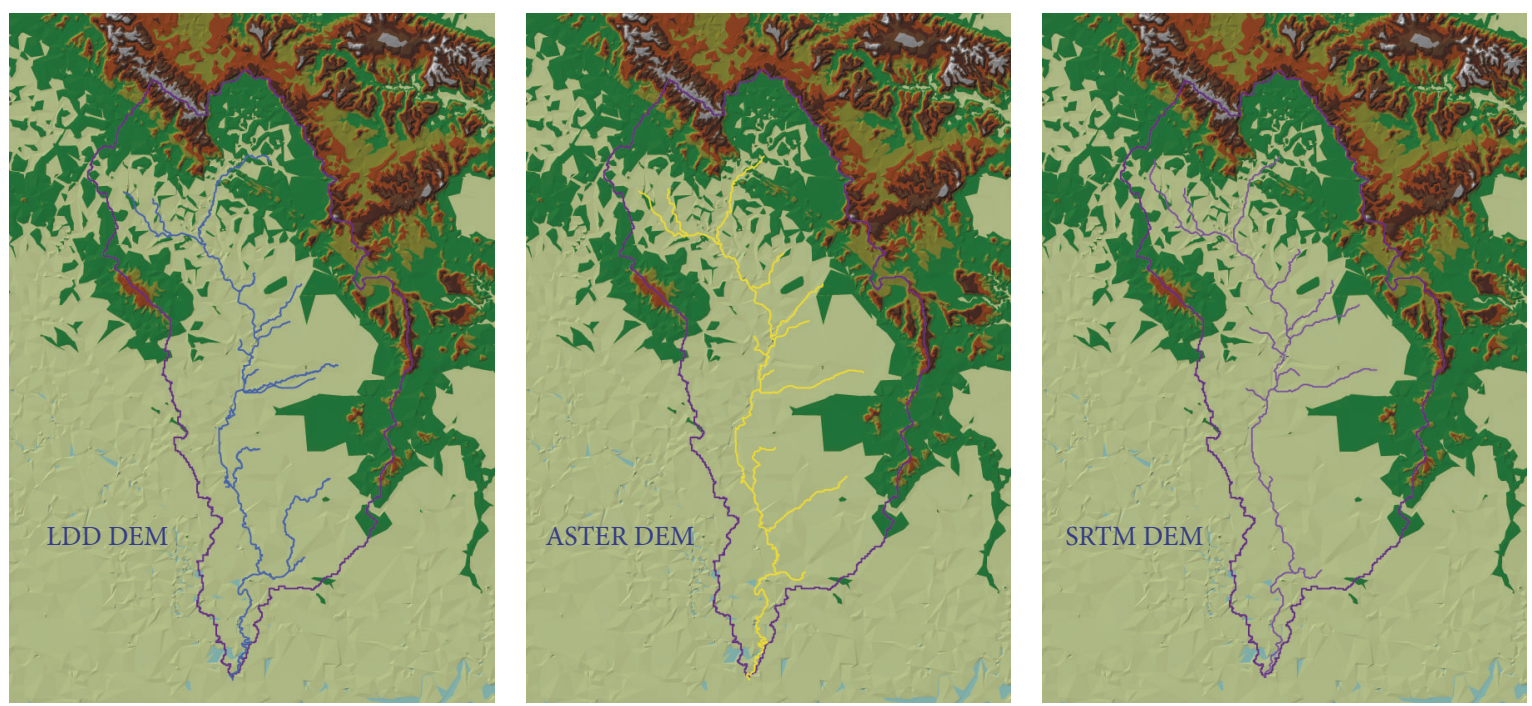

FIgURE 9: Stream lengths extracted from DEMs of Nam-Yang subbasin.

The streams' lengths extracted from the LDD DEM were used as the baseline to compare those extracted from the ASTER DEM and the SRTM DEM. The total length that was extracted from the high resolution DEMs seemed to be longer than from the coarser resolutions and had a greater length, while the watersheds were larger, as shown in Tables 10 and 11.

3.3. Impact of Main Stream Slope. The flow characteristics in the main streams and stream slopes were inherently related but differed in the stream slope impact on the velocity and discharge. The slopes of the main streams extracted from the ASTER DEM, LDD DEM, and SRTM DEM are shown in Table 12. For the stream slopes, the difference increased when the area size was larger, as shown in Table 13.

The findings of this study indicated that the resolution of the DEMs affected the watershed delineation as well as stream network and subbasin classification in SWAT models. The results obtained from all of the terrain and size areas showed that there was no significant benefit to using a finer resolution for the delineated watershed. Thus, in the planning stage, the hydrologist could use coarser resolution data to save time and cost for the area parameter in the empirical formula. These results were consistent with the results of numerous studies as follows: a study on the minimum DEM data resolution from 100 to $200 \mathrm{~m}$ found that there was less than a $10 \%$ error in the SWAT output for the flow predictions [17]. The impacts of DEM mesh size and soil map scale on the modeling results were discussed with respect to the relevant characteristics of the watershed and included in the SWAT [18]. Decreasing the resolution above $50 \mathrm{~m}$ did not substantially affect the simulation of the runoff but did have an impact on the simulation of sediment yield [19], whereas 
TABLE 10: Stream lengths extracted from LDD DEM, ASTER DEM, and SRTM DEM.

\begin{tabular}{lccc}
\hline Watersheds & LDD DEM & ASTER DEM & SRTM DEM \\
\hline Huai-Sai-Khaw (small mountainous area) & $2,859 \mathrm{~m}$ & $2,867 \mathrm{~m}$ & $2,608 \mathrm{~m}$ \\
Huai-Por-Phan (small flat area) & $3,639 \mathrm{~m}$ & $3,797 \mathrm{~m}$ & $3,704 \mathrm{~m}$ \\
Huai-Sai-Bath (medium flat area) & $128,992 \mathrm{~m}$ & $121,487 \mathrm{~m}$ & $101,486 \mathrm{~m}$ \\
Nam-Yang (large flat area) & $362,983 \mathrm{~m}$ & $302,261 \mathrm{~m}$ & $271,771 \mathrm{~m}$ \\
\hline
\end{tabular}

TABLE 11: Difference in stream lengths extracted from LDD DEM, ASTER DEM, and SRTM DEM.

\begin{tabular}{lcc}
\hline Watersheds & ASTER versus LDD & SRTM versus LDD \\
\hline $\begin{array}{l}\text { Huai-Sai-Khaw (small } \\
\text { mountainous area) }\end{array}$ & $0.28 \%$ & $8.80 \%$ \\
$\begin{array}{l}\text { Huai-Por-Phan (small } \\
\text { flat area) }\end{array}$ & $4.32 \%$ & $1.78 \%$ \\
$\begin{array}{l}\text { Huai-Sai-Bath } \\
\text { (medium flat area) }\end{array}$ & $5.82 \%$ & $21.32 \%$ \\
$\begin{array}{l}\text { Nam-Yang (large flat } \\
\text { area) }\end{array}$ & $16.73 \%$ & $25.13 \%$ \\
\hline
\end{tabular}

the SRTM DEM $90 \mathrm{~m}$ had a highly linear relationship with the LDD DEM [20]. Simulations of the daily river water discharge when based on maps with $90 \times 90$ m cell sizes in the model showed a good agreement between the calculated and measured hydrographs at the outlet of the basin [21].

Many common parameters depend both on the size of the basin and on the scale of the digital elevation model used for the computations. The results showed that the watershed sizes and shapes obtained were only slightly different when using the LDD $5 \mathrm{~m}$, ASTER $30 \mathrm{~m}$, and SRTM $90 \mathrm{~m}$. That did not mean that the LDD $5 \mathrm{~m}$, ASTER $30 \mathrm{~m}$, and SRTM $90 \mathrm{~m}$ generated similar accuracies, as the land use/cover and the individual scene DEMs that were stacked to create the final averaged DEM elevation value also affected the accuracies of the remote sensing-derived DEMs.

It can be seen that the ASTER DEM is a good quality DEM that meets the requirements and therefore enables the hydrologist to create the watershed and parameters. The quality of the DEM depends primarily on the input data in the large areas. Somehow the LDD DEM had voids in the focus areas that caused the shape of the basin to be inconsistent with the topography (checked by visual inspection with orthophotos), as shown in Figures 10 and 11.

In some hydrologic models the slope derived from the DEM does not influence the output data. A coarser resolution DEM could be used to reduce the running time of the model because the time needed to delineate a watershed is a function of the grid (DEM) size. In addition, more cells in a grid will take too much processing time, so the programs will use too much of the computer's resources. However, in some models, the slope of the area is an important factor, such as in a soil erosion model, as the slope can affect the soil erosion significantly. Then, using a map with higher accuracy as the model input is necessary.

In the Huai-Sai-Bath subbasin, with an area of about $600 \mathrm{~km}^{2}$, the LDD DEM file size was $268 \mathrm{MB}$ while
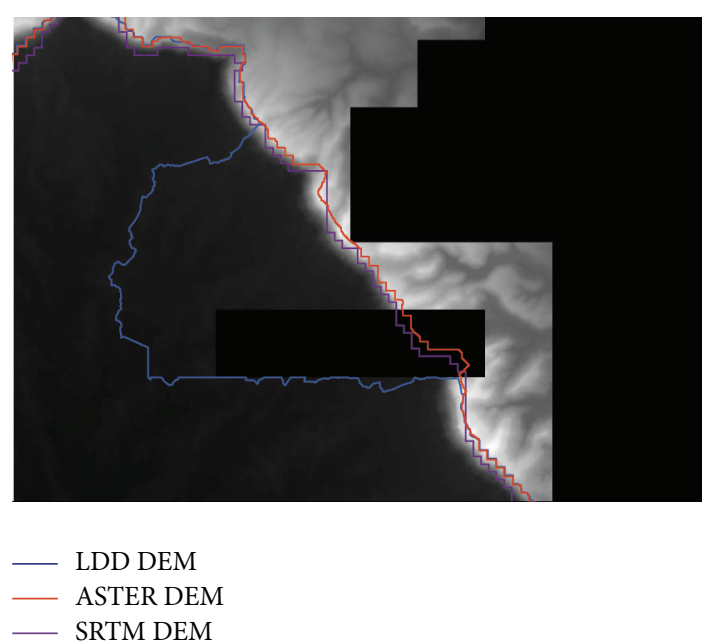

FIgure 10: Void in LDD DEM.
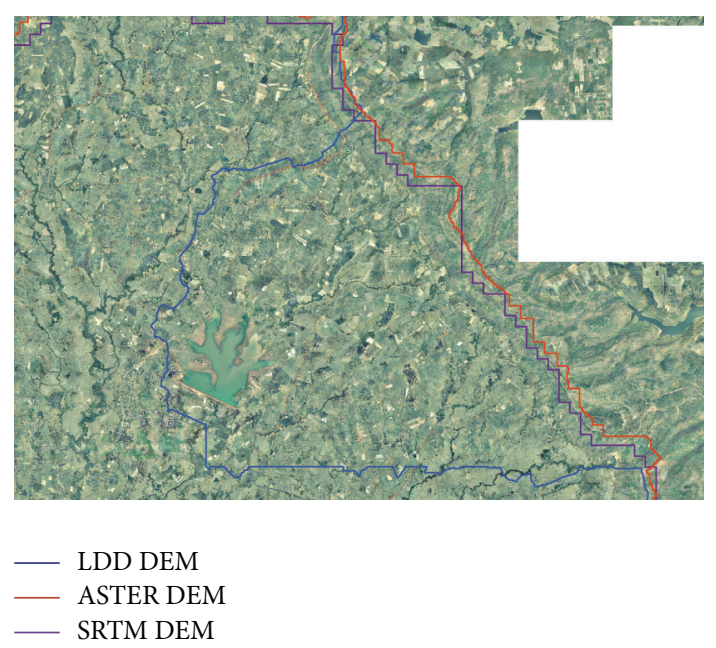

FIGURE 11: Topographic checking via visual inspection.

the ASTER DEM file size was $1.96 \mathrm{MB}$, which is more than 100 times the size and takes 10 times the time to run the model (ASTER DEM takes $10 \mathrm{~min}$; LDD DEM takes $300 \mathrm{~min}$ ). In the Nam-Yang subbasin, with an area of more than $4,000 \mathrm{~km}^{2}$, it takes more than $2 \mathrm{~GB}$ of RAM to run the model with the LDD DEM, and it takes 20 times the time to run when compared to the ASTER DEM (ASTER DEM takes 30 minutes; LDD DEM takes 600 minutes). 
TABLE 12: Slopes of main streams extracted from LDD DEM, ASTER DEM, and SRTM DEM.

\begin{tabular}{lccc}
\hline Watershed & LDD DEM & ASTER DEM & SRTM DEM \\
\hline Huai-Sai-Khaw (small mountainous area) & 0.898 & 0.872 & 0.844 \\
Huai-Por-Phan (small flat area) & 0.290 & 0.316 & 0.297 \\
Huai-Sai-Bath (medium flat area) & 0.098 & 0.146 & 0.108 \\
Nam-Yang (large flat area) & 0.049 & 0.017 & 0.073 \\
\hline
\end{tabular}

TABLE 13: Difference in stream slopes extracted from LDD DEM, ASTER DEM, and SRTM DEM.

\begin{tabular}{lcc}
\hline Watershed & ASTER versus LDD & SRTM versus LDD \\
\hline $\begin{array}{l}\text { Huai-Sai-Khaw (small } \\
\text { mountainous area) }\end{array}$ & $2.95 \%$ & $3.23 \%$ \\
$\begin{array}{l}\text { Huai-Por- Phan } \\
\text { (small flat area) }\end{array}$ & $8.32 \%$ & $6.04 \%$ \\
$\begin{array}{l}\text { Huai-Sai-Bath } \\
\text { (medium flat area) }\end{array}$ & $32.98 \%$ & $26.35 \%$ \\
$\begin{array}{l}\text { Nam-Yang (large flat } \\
\text { area) }\end{array}$ & $193.36 \%$ & $336.92 \%$ \\
\hline
\end{tabular}

\section{Conclusion}

The total length of the streamline, the main channel slope, the watershed area, and the area slope were significantly different when using the three resolutions of DEM to delineate. The watershed sizes and shapes obtained were only slightly different, whereas the area slopes obtained were significantly different. These differences decreased when the area sizes of the data increased. The resolution of the DEM had a significant effect on the area slope, as the area slope decreased when the resolution of the DEM used was higher. The total stream length extracted from the higher resolution was longer than when the coarser resolution of the DEM was used. These differences increased when the area sizes of the data increased. The stream line extracted from the DEM had increased branching and small streams were visualized well when the resolution of the DEM increased. The slopes obtained for the main streams from all DEMs were only slightly different when using smaller area sizes, whereas using larger area sizes they were quite different. The ASTER DEM is a good quality DEM that meets the requirements, thereby enabling the hydrologist to create the watershed and parameters. The ASTER DEM can be used rather than a finer resolution DEM for the model input to save time for the model calibration and validation.

\section{Conflict of Interests}

The authors declare that there is no conflict of interests regarding the publication of this paper.

\section{Acknowledgments}

This research was financially supported by Mahasarakham University; the authors would like to acknowledge Mahasarakham University. They are thankful for the DEM dataset provided by the Land Development Department, Thailand.

\section{References}

[1] K. Saha and M. Munro-Stasiuk, "Automated extraction of drumlins from digital elevation models through objectoriented classification," in Proceedings of the American Society for Photogrammetry and Remote Sensing Annual Conference (ASPRS '09), pp. 1-10, Baltimore, Md, USA, March 2009.

[2] B. Singh and J. Dowerah, "ASTER DEM based studies for geological investigation around Singhbhum Shear Zone (SSZ) in Jharkhand, India," Journal of Geographic Information System, vol. 2, no. 1, pp. 11-14, 2010.

[3] S. Suganthi and K. Srinivasan, "Digital elevation model generation and its application in landslide studies using cartosat-1," International Journal of Geomatics and Geosciences, vol. 1, no. 1, pp. 41-50, 2010.

[4] A. W. Alansi, M. S. Amin, G. Abdul Halim, H. Z. Shafri, and W. Aimrun, "Validation of SWAT model for stream flow simulation and forecasting in Upper Bernam humid tropical river basin, Malaysia," Hydrology and Earth System Sciences Discussions, vol. 6, no. 6, pp. 7581-7609, 2009.

[5] S. Lin, C. Jing, V. Chaplot et al., "Effect of DEM resolution on SWAT outputs of runoff, sediment and nutrients," Hydrology and Earth System Sciences, vol. 7, no. 4, pp. 4411-4435, 2010.

[6] S. G. Thampi, K. Y. Raneesh, and T. V. Surya, "Influence of scale on SWAT model calibration for streamflow in a river basin in the Humid Tropics," Water Resources Management, vol. 24, no. 15, pp. 4567-4578, 2010.

[7] Ö. Mutluoğlu, "Investigation of the effect of land slope on the accuracy of digital elevation model (DEM) generated from various sources," Scientific Research and Essays, vol. 5, no. 11, pp. 1384-1391, 2010.

[8] A. O. Opere and B. N. Okello, "Hydrologic analysis for river Nyando using SWAT," Hydrology and Earth System Sciences Discussions, vol. 8, no. 1, pp. 1765-1797, 2011.

[9] D. Prodanovic, M. Stanic, V. Milivojevic, Z. Simic, and M. Arsic, "DEM-based GIS algorithms for automatic creation of hydrological models data," Journal of the Serbian Society for Computational Mechanics, vol. 3, no. 1, pp. 64-85, 2009.

[10] T. Bolch and U. Kamp, "Glacier mapping in high mountains using DEMs, Landsat and ASTER data," in Proceedings of the 8th International Symposium on High Mountain Remote Sensing Cartography, pp. 37-48, 2006.

[11] J. G. Arnold, R. Srinivasan, R. S. Muttiah, and J. R. Williams, "Large area hydrologic modeling and assessment part I: model development," Journal of the American Water Resources Association, vol. 34, no. 1, pp. 73-89, 1998.

[12] P. W. Gassman, M. R. Reyes, C. H. Green, and J. G. Arnold, "The soil and water assessment tool: historical development, 
applications, and future research directions," Transactions of the $A S A B E$, vol. 50, no. 4, pp. 1211-1250, 2007.

[13] V. Chaplot, "Impact of spatial input data resolution on hydrological and erosion modeling: recommendations from a global assessment," Physics and Chemistry of the Earth, Parts $A / B / C$, vol. 67-69, pp. 23-35, 2014.

[14] M. L. Tan, D. L. Ficklin, B. Dixon, A. L. Ibrahim, Z. Yusop, and V. Chaplot, "Impacts of DEM resolution, source, and resampling technique on SWAT-simulated streamflow," Applied Geography, vol. 63, pp. 357-368, 2015.

[15] R. Jones, "Algorithms for using a DEM for mapping catchment areas of stream sediment samples," Computers \& Geosciences, vol. 28, no. 9, pp. 1051-1060, 2002.

[16] O. Boonklong, M. Jaroensutasinee, and K. Jaroensutasinee, "Computation of D8 flow line at Ron Phibun Area, Nakhon Si Thammarat, Thailand," World Academy of Science, Engineering and Technology, vol. 33, pp. 1-4, 2007.

[17] V. Chaplot, "Impact of DEM mesh size and soil map scale on SWAT runoff, sediment, and $\mathrm{NO}_{3}-\mathrm{N}$ loads predictions," Journal of Hydrology, vol. 312, no. 1-4, pp. 207-222, 2005.

[18] I. Chaubey, A. S. Cotter, T. A. Costello, and T. S. Soerens, "Effect of DEM data resolution on SWAT output uncertainty," Hydrological Processes, vol. 19, no. 3, pp. 621-628, 2005.

[19] G. Ghaffari, "The impact of DEM resolution on runoff and sediment modelling results," Research Journal of Environmental Sciences, vol. 5, no. 8, pp. 691-702, 2011.

[20] C. Waisurasingha, M. Aniya, A. Hirano, J. Sang-Arun, and W. Sommut, "Application of remote sensing and GIS for improving rice production in flood-prone areas: a case study in Lower ChiRiver Basin, Thailand," Japan Agricultural Research Quarterly, vol. 42, no. 3, pp. 193-201, 2008.

[21] A. Kabir, M. Mahdavi, A. Bahremand, and N. Noora, "Application of a geographical information system (GIS) based hydrological model for flow prediction in Gorganrood river basin, Iran," African Journal of Agricultural Research, vol. 6, no. 1, pp. 35-45, 2011. 


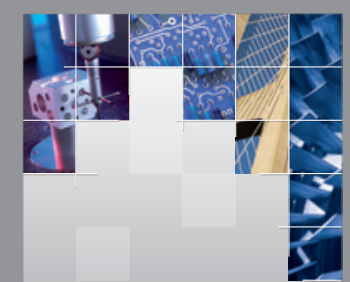

\section{Enfincering}
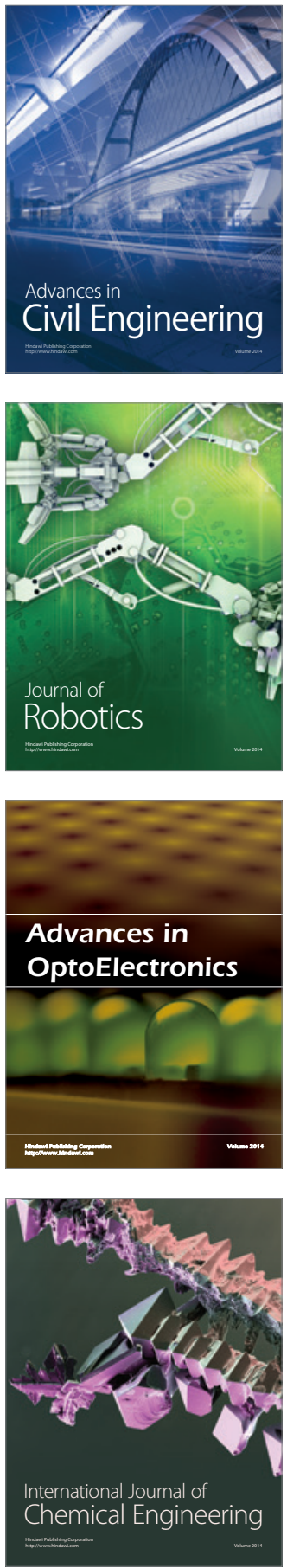

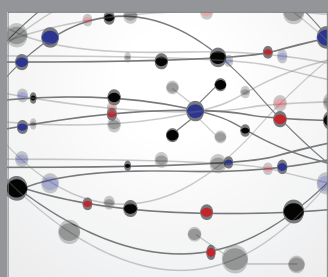

The Scientific World Journal

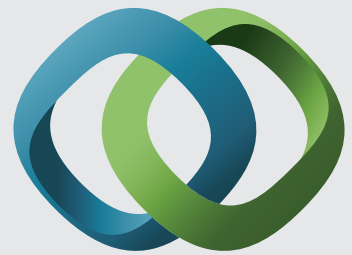

\section{Hindawi}

Submit your manuscripts at

http://www.hindawi.com
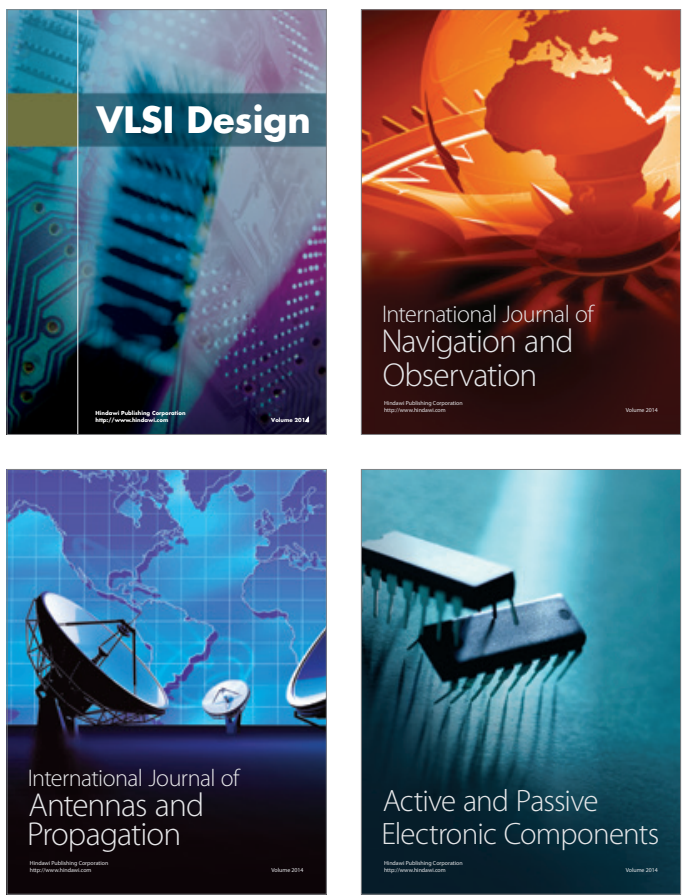
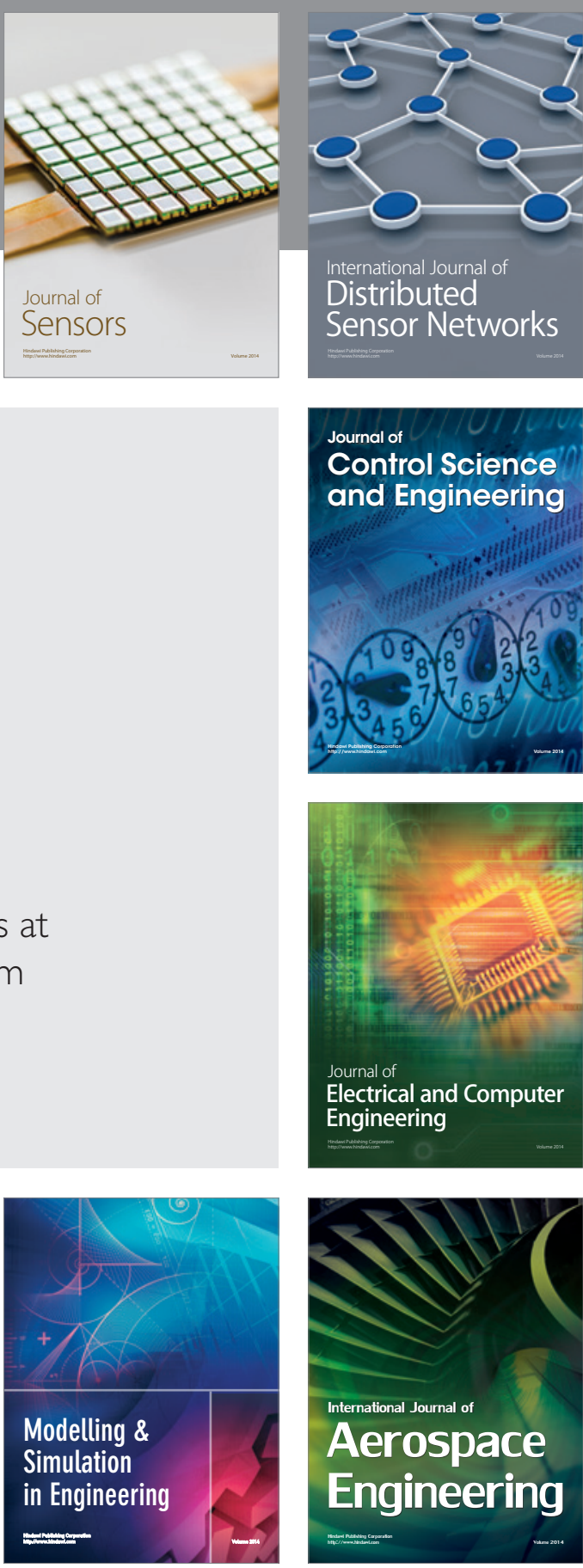

International Journal of

Distributed

Sensor Networks

Journal of

Control Science

and Engineering
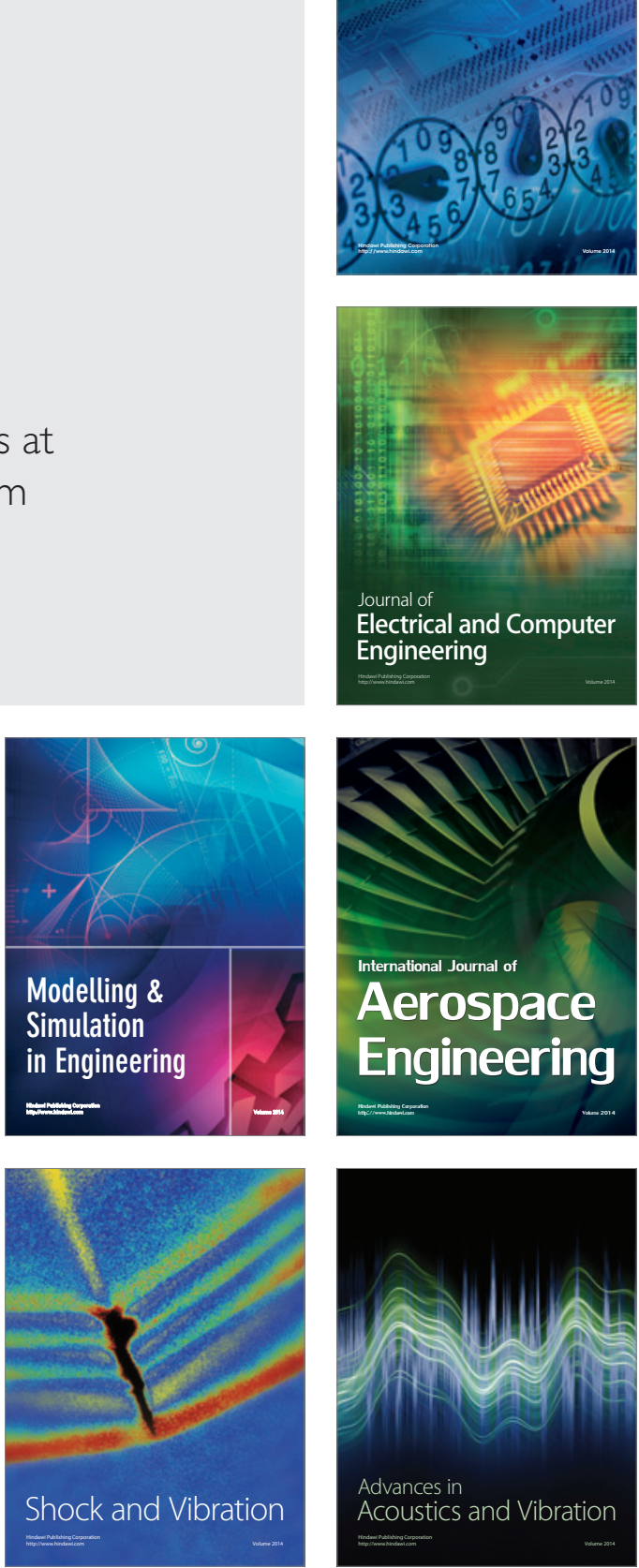